\title{
Management of pulmonary arteriovenous malformations in pulmonary hypertensive patients: a pressure to embolise?
}

\section{C.L. Shovlin, J.S.R. Gibbs and J.E. Jackson}

$\mathbf{P}$ ulmonary arteriovenous malformations (PAVMs) carry significant risks [1, 2]. Pulmonary arterial blood passing through these right-to-left shunts cannot be oxygenated, leading to hypoxaemia, with arterial oxygen tension and arterial oxygen saturation $\left(\mathrm{S}_{\mathrm{a}} \mathrm{O}_{2}\right)$ inversely related to the size of the shunt fraction. The fragile wall of the PAVM sac may rupture, leading to haemoptysis or haemothorax [3]. In addition, the absence of a filtering capillary bed allows particulate matter to reach the systemic circulation where it impacts in other capillary beds, including those of the cerebral circulation, resulting in embolic cerebrovascular accidents and cerebral abscesses. In a recent series of 219 patients that corrected for ascertainment bias, the rates for ischaemic stroke and cerebral abscess were $11.3 \%$ and $9 \%$, respectively, with risks unrelated to PAVM severity or symptoms [4]. Treatment of PAVMs by embolisation is an effective means of reducing lifetime risks of paradoxical embolic stroke and cerebral abscess [4], improving oxygenation $[1,5,6]$, and treating PAVM-induced haemoptysis [3, 7]. Embolisation usually carries minimal risk in expert hands and, as a result, is generally offered to patients with PAVMs of a size amenable to embolisation, irrespective of the presence of respiratory symptoms.

PAVMs themselves have a lower vascular resistance than that of the surrounding normal lung, due to the absence of a microvascular network of capillary vessels. However, most individuals with PAVMs have underlying hereditary haemorrhagic telangiectasia (HHT), now recognised to carry an independent risk of pulmonary hypertension (PH) [8]. HHT is inherited as an autosomal dominant trait, and is most commonly caused by mutations in the genes for endoglin (HHT type 1) or activin receptor-like kinase-1 (HHT type 2) [9]. The condition, which affects one in $5-8,000$ Europeans $[10,11]$, is classically diagnosed by the consensus criteria of nosebleeds, mucocutaneous telangiectasia, visceral arteriovenous malformations (AVMs) and family history [12]. HHT-related PH occurs in two main settings: 1) a post-capillary $\mathrm{PH}$ in the context of high-output cardiac failure secondary to hepatic AVMs with elevated pulmonary artery wedge pressure and normal or near-normal pulmonary vascular resistance (PVR); and 2) a true pulmonary arterial hypertension (PAH) phenotype [13] characterised by normal pulmonary artery wedge pressure and markedly raised PVR [6]. While severe $\mathrm{PH}$ in unselected HHT cohorts is rare [6, 14], and PAVMs and PH are more common in different HHT genotypes (type 1 for PAVMs, type 2 for both forms of PH [15]), a small group of HHT patients have both PAVMs and severe PH.

The presence of PAVMs does not modify the treatment of $\mathrm{PH}$. The question is, should the presence of $\mathrm{PH}$ modify recommended treatments for PAVMs and, if so, for which patients?

\section{PH MODIFICATION OF THE NATURAL HISTORY OF PAVMS}

As noted in table 1, PAVM risks differ in the presence of $\mathrm{PH}$. Recent data demonstrate that the risk of ischaemic stroke is substantially lower in PAVM patients with higher pulmonary artery pressure $(P \mathrm{pa})$ : the hazard ratio fell with each $1 \mathrm{mmHg}$ rise in mean $P_{\mathrm{pa}}$ [4]. Conversely, the presence of elevated PAVM sac perfusion pressures, either due to $\mathrm{PH}$ or in the setting of a systemic arterial supply to PAVM sacs [19], appears to place patients at higher risk of lifethreatening haemorrhage from PAVMs, as has been described in the present issue of the European Respiratory Review [16]. While it is unclear whether $\mathrm{PH}$ precipitates the development of PAVMs in susceptible individuals, there are rare case reports suggesting $\mathrm{PH}$ may be associated with rapid growth of PAVMs [18].

\section{PH MODIFICATION OF PAVM TREATMENT- RELATED RISKS}

PAVM embolisation abolishes low resistance pathways for pulmonary blood flow and, therefore, might be expected to elevate $P$ pa. Isolated case reports, including fatalities [20], highlight the potential risks of such an increase. However,

\section{AFFILIATIONS}

Imperial College, London, and Hammersmith Hospital, Imperial College Healthcare NHS Trust, London, UK.

\section{CORRESPONDENCE}

C. Shovlin

Respiratory Medicine,

Hammersmith Hospital

Du Cane Road

London

W12 ONN

UK

E-mail: c.shovlin@imperial.ac.uk

Received:

December 172008

Accepted:

December 182008

STATEMENT OF INTEREST

None declared.

PROVENANCE

Submitted article, peer reviewed.

European Respiratory Review Print ISSN 0905-9180

Online ISSN 1600-0617 


\section{TABLE 1 Pulmonary arteriovenous malformation (PAVM) risks}

\begin{tabular}{|c|c|c|}
\hline Ischaemic stroke & $11.3 \%$ & $\begin{array}{l}\text { Lower: HR } 0.89(95 \% \mathrm{Cl} 0.83-0.95 \\
\left.\qquad \mathrm{p}=6.2 \times 10^{-5}\right)[4]\end{array}$ \\
\hline Brain abscess & $9 \%$ & Unchanged [4] \\
\hline \multicolumn{3}{|c|}{ Dyspnoea according to $\mathrm{Sa}, \mathrm{O}_{2}$ quartiles ${ }^{\#}$} \\
\hline$>96$ & $1.5 \%$ & \\
\hline$<88$ & $37 \%$ & \\
\hline PAVM-related haemorrhage & $<10 \%$, usually minor & Possibly more common and severe [16] \\
\hline Migraine & Two-fold excess [17] & No data \\
\hline Growth & Generally nil/slow ${ }^{+}$ & Possibly increased [18] \\
\hline
\end{tabular}

$\mathrm{PH}$ : pulmonary hypertension; $\mathrm{Sa}_{2} \mathrm{O}_{2}$ : arterial oxygen saturation; HR: hazard ratio per mmHg increase; Cl: confidence interval. ${ }^{*}:$ reported in [4, 6]; ${ }^{\bullet}:$ haemoptysis haemothorax; ${ }^{+}$: except during puberty and pregnancy.

a recent study of 43 patients demonstrated that for most individuals, successful PAVM embolisation resulting in improved $\mathrm{Sa}, \mathrm{O}_{2}$ did not result in a sustained or acute change in $P$ pa [6]. In half of the cases, including one individual with post-capillary $\mathrm{PH}$ due to left ventricular disease, embolisation led to a fall in $P$ pa, which was attributed to the described reduction in cardiac output [5].

PAVM patients clearly differ in their haemodynamic responses to embolisation. Several authors have pointed out that deleterious rises may relate to underlying hepatic AVMs [6, 16, 20]. Temporary balloon occlusion of the PAVM before definitive embolisation has been suggested in order to identify which patients are at risk of such an increase [16, 20]; however, in the one reported individual, test balloon occlusion did not predict a substantial $22 \mathrm{mmHg}$ rise in mean $P$ pa following definitive embolisation [6].

\section{INTERPRETATION}

So, should embolisation of PAVMs be performed in patients with severe pre-existing $\mathrm{PH}$ ? The most common indications for PAVM embolisation are to reduce the risk of paradoxical embolic stroke and, for individuals with hypoxaemia, to improve dyspnoea and exercise tolerance. Since the risk of paradoxical embolic stroke is substantially lower in individuals with higher $P$ pa [4], and symptomatic relief from dyspnoea should not be expected for patients with $\mathrm{PH}$ and $\mathrm{Sa}_{1} \mathrm{O}_{2}>90 \%$, as was the case in all four patients with severe $\mathrm{PH}$ in a recent study [6], SHOVLIN et al. [6] suggested that for the majority of patients with pre-existing severe PAH the risks of PAVM embolisation outweigh potential benefits. In the present issue of the Review, the case report by MONTANI et al. [16] highlights the risk of later development of haemothorax but, as has been reported in the pregnancy setting (where 1.02\% (95\% confidence interval $0.13-1.92 \%$ ) of $484 \mathrm{PAVM} / \mathrm{HHT}$ pregnancies resulted in a major PAVM bleed), there is no reported evidence that embolisation of PAVMs for individuals who have not experienced a complication reduces the risk of later haemorrhage [7]. Thus, in general, for patients with severe $\mathrm{PH}$ we would not interpret the risk-benefit considerations in favour of PAVM embolisation.
The most difficult judgements relate to individuals with severe pulmonary hypertension and active major haemoptysis or haemothorax in whom pulmonary arteriovenous malformationrelated haemorrhage may be a terminal event. In a previous study of pregnant females (without pulmonary hypertension) [7], and in pulmonary hypertension cases known to the current authors, there was time for emergency intervention to be performed after the onset of herald symptoms (haemoptysis or chest pain). In such an emergency setting, patients and their physicians may consider the risks of precipitating a further increase in pulmonary artery pressure justifiable. In the present authors' opinion, even if test balloon occlusion is performed and appears satisfactory, all patients should be warned of a potential fatal increase in pulmonary artery pressure. Further data are required to assess whether particular categories of pulmonary hypertension carry lower risks.

\section{ACKNOWLEDGEMENTS}

The authors would like to thank the National Institute for Health Research Biomedical Research Centre Funding Scheme and British hereditary haemorrhagic telangiectasia patients and families for their support. The authors would like to apologise to colleagues whose work they were unable to cite.

\section{REFERENCES}

1 Cottin V, Dupuis-Girod S, Lesca G, Cordier JF. Pulmonary vascular manifestations of hereditary hemorrhagic telangiectasia (Rendu-Osler disease). Respiration 2007; 74: 361-378.

2 Shovlin CL, Jackson JE, Hughes JMB. Pulmonary arteriovenous malformations and other pulmonary vascular disorders. In: Mason RJ, Courtney Broaddus V, Murray JF, Nadel J, eds. Murray and Nadel's Textbook of Respiratory Medicine. 4th Edn. Philadelphia, Elsevier Saunders, 2005; pp. 1480-1501.

3 Ference BA, Shannon TM, White RI Jr, Zawain M, Burdge CM. Life threatening pulmonary hemorrhage with pulmonary arteriovenous malformations and hereditary hemorrhagic telangiectasia. Chest 1994; 106: 1387-1392. 
4 Shovlin CL, Jackson JE, Bamford KB, et al. Primary determinants of ischaemic stroke/brain abscess risks are independent of severity of pulmonary arteriovenous malformations in hereditary haemorrhagic telangiectasia. Thorax 2008; 63: 259-266.

5 Terry PB, Barth KH, Kaufman SZ, White RI Jr. Balloon embolisation for the treatment of pulmonary arteriovenous fistulas. N Engl J Med 1980; 302: 1189-1190.

6 Shovlin CL, Tighe HC, Davies RJ, Gibbs JS, Jackson JE. Embolisation of pulmonary arteriovenous malformations: no consistent effect on pulmonary artery pressure. Eur Respir J 2008; 32: 162-169.

7 Shovlin CL, Sodhi V, McCarthy A, Lasjaunias P, Jackson JE, Sheppard MN. Estimates of maternal risks of pregnancy for women with hereditary haemorrhagic telangiectasia (Osler-Weber-Rendu syndrome): suggested approach for obstetrics services. BJOG 2008; 115: 1108-1115.

8 Hoeper M, Humbert M. A message on the lips. Eur Respir J 2008; 32: 15-16.

9 Abdalla SA, Letarte M. Hereditary haemorrhagic telangiectasia: current views on genetics and mechanisms of disease. J Med Genet 2006; 43: 97-110.

10 Bideau A, Brunet G, Heyer E, Plauchu H, Robert JM. An abnormal concentration of cases of Rendu-Osler disease in the Valserine valley of the French Jura: a geneological and demographic study. Ann Hum Biol 1992; 19: 233-247.

11 Kjeldsen AD, Vase P, Green A. Hereditary haemorrhagic telangiectasia: a population-based study of prevalence and mortality in Danish patients. J Intern Med 1999; 245: 31-39.

12 Shovlin CL, Guttmacher AE, Buscarini E, et al. Diagnostic criteria for hereditary hemorrhagic telangiectasia (RenduOsler-Weber syndrome). Am J Med Genet 2000; 91: 66-67.
13 Trembath RC, Thomson JR, Machado RD, et al. Clinical and molecular features of pulmonary hypertension in patients with hereditary hemorrhagic telangiectasia. $N$ Engl J Med 2001; 345: 325-334.

14 Olivieri C, Lanzarini L, Pagella F, et al. Echocardiographic screening discloses increased values of pulmonary artery systolic pressure in 9 of 68 unselected patients affected with hereditary hemorrhagic telangiectasia. Genet Med 2006; 8: 183-190.

15 Letteboer TG, Mager H, Snijder RJ, et al. Genotypephenotype relationship in hereditary haemorrhagic telangiectasia. J Med Genet 2006; 43: 371-377.

16 Montani D, Price LC, Girerd D, et al. Fatal rupture of pulmonary arteriovenous malformation in hereditary haemorrhagic telangiectasis and severe pulmonary arterial hypertension. Eur Respir Rev 2008; 18: 42-46.

17 Post MC, van Gent MW, Snijder RJ, et al. Pulmonary arteriovenous malformations and migraine: a new vision. Respiration 2008; 76: 228-233.

18 Chow LT, Chow WH, Ma KF. Pulmonary arteriovenous malformation. Progressive enlargement with replacement of the entire right middle lobe in a patient with concomitant mitral stenosis. Med J Aus 1993; 158: 632-634.

19 Sagara K, Miyazono N, Inoue $H$, Ueno K, Nishida $H$, Nakajo M. Recanalization after coil embolotherapy of pulmonary arteriovenous malformations: study of longterm outcome and mechanism for recanalization. AJR Am J Roentgenol 1998; 170: 727-730.

20 Haitjema T, ten Berg JM, Overtoom TT, Ernst JM, Westermann CJ. Unusual complications after embolization of a pulmonary arteriovenous malformation. Chest 1996; 109: 1401-1404. 